\title{
Into the out: safety issues in interhospital transport of the critically ill
}

\author{
Andreas Valentin $^{1 *}$ and Carole Schwebel ${ }^{2}$
}

(C) 2016 Springer-Verlag Berlin Heidelberg and ESICM

For an ICU patient the world outside in some way resembles outer space for an astronaut staying in the space shuttle. There is no survival without life-saving technical equipment and after leaving the safe haven (ICU or space shuttle) the return or the journey to the next safe place might be a real challenge. For the ICU patient this becomes particular true when leaving the hospital environment for an interhospital transport. In contrast to the astronaut a critically ill patient will not be in a self-competent status; he or she is completely dependent on the care of highly educated and competent physicians and nurses using the most advanced medical technology and therapies.

Interestingly, safety of ICU patients during a transport has only recently been the focus of intensive care research. Although patient safety has received a lot of interest over the years, publications about safety of critically ill patients on the move were rare with the exception of primary emergency patient transports. One reason might be the difficulty in defining a safe transport; is it when the patient experiences no transport-related deterioriation and arrives at least in the same condition as at departure, or is it when there is an absence of critical events like an unintended extubation or the failure of equipment? Interhospital transports carry a particular risk regarding the safe functioning of transport equipment. In a Dutch study involving 353 interhospital transports, 55 technical problems were encountered, ranging from problems with the gas supply and electricity to problems with the medical equipment and the trolleys, as well as with some functions of the ambulance itself [1].

Unquestionably, the opportunities for transportrelated errors and events are numerous. Most ICU

\footnotetext{
*Correspondence: andreas.valentin@kh-schwarzach.at

1 Department of Internal Medicine, Kardinal Schwarzenberg Hospital, Schwarzach, Austria

Full author information is available at the end of the article
}

patients' transports are characterised by a less sophisticated monitoring or treatment (e.g. a more simple mode of ventilation), additional movements (e.g. lifting of a patient) or exposure to altered environmental conditions (temperature, altitude, acceleration, unfamiliar or closed and narrow surroundings), not to forget limited diagnostic and therapeutic resources in addition to the frequent lack of skilled escort or senior staff. Indeed, an important question concerns the composition of the transport team. While it seems intuitively most likely that a dedicated transport team should be advantageous, there are few data supporting this assumption. Back in 2002 a study from Finland concluded that "Long-distance interhospital ground transfer of even critically ill patients with severe unstable respiratory and circulatory failure is safe if a dedicated transport team and a specially equipped transport vehicle are used" [2]. Obviously ventilated patients are to be considered as a group with increased risk during any kind of transport and clearly require skilled accompanying medical staff. In a Scottish study on interhospital transfers of acutely ill patients, the incidence of unsecured medical equipment and equipment failures in ventilated patients was significantly lower in dedicated transport teams [3]. But what does a dedicated transport team mean? Should the professional profile of a transport team of a critically ill patient resemble the conditions of an ICU as closely as possible? If the answer is yes, is a certified intensive care physician mandatory for such a transport?

In a recent article in Intensive Care Medicine, van Lieshout and colleagues report on a study comparing nurses versus physician-led interhospital critical care transport [4]. A total of 298 patients were randomised and allocated either to a transport team consisting of critical care nurses and paramedics or critical care nurses and critical care physicians. A main signal from this study is an incidence rate of critical events affecting 
$16 \%$ of all patients. One explanation for this unexpected high rate is the use of an electronic health record during transport, which enhanced the continuous and objective observation of potential episodes of physiologic deterioration. The primary study outcome combined such clinical events with technical events like equipment failure. In short, the study could not confirm the hypothesis that nurse-led transports are non-inferior to physicianled transports with respect to the occurrence of critical events. In other words, when considering the results of this study we cannot be sure that in nurse-led transports compared to physician-led transports an equal and not a higher rate of critical events is likely.

Non-inferiority is not only a somewhat difficult to understand double negative term but needs the definition of a range of equality. The authors of the recent study chose a non-inferiority margin of $3 \%$ as clinically acceptable. Obviously this margin is subjective and debatable, and the main result of the study (no confirmation of non-inferiority of nurse-led transport) could have been read and interpreted differently with another margin for non-inferiority. This is one of the reasons why the results of this study need to be interpreted with caution. Other reasons consist in the patient selection (e.g. exclusion of patients with a need for emergency transport between hospitals), the single-centre design, and the use of highly trained transport staff (ICU nurses and physicians) exclusively from one academic medical centre. The last condition does not necessarily reflect current practice or organization and subsequently the applicability in many regions of Europe.

Even though this study does not definitively answer the question about equality of nurse versus physician-led ICU transport, it carries a much more important signal. Although transports were performed by dedicated and highly educated transport teams, an unexpected high rate of critical events occurred. First, one could wonder about the hypothetical results with less educated teams. Second, the response and the ability to resolve a critical event might be a more relevant performance indicator for a transport team than the pure rate of events. A transport might impact the patient status beyond the arrival at the destination ICU. The interruption or downgrading of critical care processes during transport can lead to pathophysiological derangements if no proper and timesensitive adaption is performed [5].

Patient safety in general is about minimising risks $[6,7]$. Although there is no way to reduce the risk of a critical care transport to zero, several measures with the potential to reduce risk have been described (Fig. 1). To highlight just one important step in the process, the planning and preparation of a transport should be mentioned here. This step includes the detailed assessment of

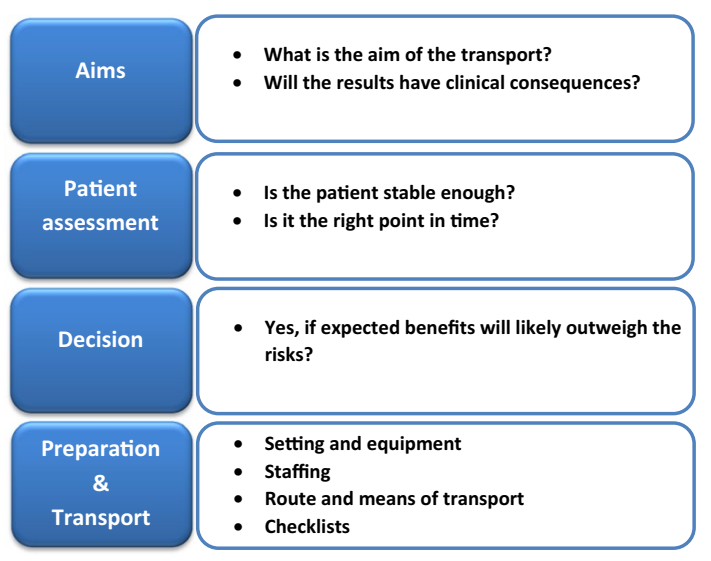

Fig. 1 How to minimise transport-associated risks for ICU patients: issues for consideration

a patient, and elaboration of a risk-benefit ratio by asking the question "will this transport likely result in findings or procedures that will ultimately benefit this patient?" It has been shown that the use of checklists is not only helpful in structuring this process but is associated with a reduction of incidents during the transport of critically ill patients [8]. Programs to enhance patient safety should include checklists for the preparation and realisation of critical care transports either within or between hospitals $[9,10]$. Centralisation of specialised critical care services will likely increase the demand for critical care transports further. It is more than clear that ICU teams, hospital and regional administrations need to develop a safe, timely and comprehensive approach to cover and face this growing demand. Although research outside the ICU might be challenging, there are still many issues, like the ideal composition of the transport team, to be answered.

\section{Author details}

${ }^{1}$ Department of Internal Medicine, Kardinal Schwarzenberg Hospital,

Schwarzach, Austria. ${ }^{2}$ Medical Intensive Care Unit, Albert Michallon Teaching Hospital, Alpes University Grenoble, Grenoble, France.

Compliance with ethical standards

\section{Conflicts of interest}

On behalf of all authors, the corresponding author states that there is no conflict of interest.

Received: 11 May 2016 Accepted: 12 May 2016

Published online: 20 May 2016

\section{References}

1. Droogh JM, Smit M, Hut J, de Vos R, Ligtenberg JJ, Zijlstra JG (2012) Inter-hospital transport of critically ill patients; expect surprises. Crit Care 16(1):R26. doi:10.1186/cc11191 
2. Uusaro A, Parviainen I, Takala J, Ruokonen E (2002) Safe long-distance interhospital ground transfer of critically ill patients with acute severe unstable respiratory and circulatory failure. Intensive Care Med 28(8):1122-1125. doi:10.1007/s00134-002-1348-9

3. Fried MJ, Bruce J, Colquhoun R, Smith G (2010) Inter-hospital transfers of acutely ill adults in Scotland. Anaesthesia 65(2):136-144. doi:10.1111/j.1365-2044.2009.06165.x

4. van Lieshout EJ et al (2016) Nurses versus physician-led interhospital critical care transport: a randomized non-inferiority trial. Intensive Care Med. doi:10.1007/s00134-016-4355-y

5. Schwebel C, Clec'h C, Magne S, Minet C, Garrouste-Orgeas M, Bonadona A, Dumenil AS, Jamali S, Kallel H, Goldgran-Toledano D, Marcotte G, Azoulay E, Darmon M, Ruckly S, Souweine B, Timsit JF (2013) Safety of intrahospital transport in ventilated critically ill patients: a multicenter cohort study. Crit Care Med 41(8):1919-1928. doi:10.1097/ CCM.0b013e31828a3bbd
6. Valentin A (2013) Approaches to decreasing medication and other care errors in the ICU. Curr Opin Crit Care 19(5):474-479. doi:10.1097/ MCC.0b013e328364d4f9

7. Garrouste-Orgeas M, Valentin A (2013) What's new for patient safety in the ICU? Intensive Care Med. doi:10.1007/s00134-013-3013-x

8. Berube M, Bernard F, Marion H, Parent J, Thibault M, Williamson DR, Albert M (2013) Impact of a preventive programme on the occurrence of incidents during the transport of critically ill patients. Intensive Crit Care Nurs 29(1):9-19. doi:10.1016/j.iccn.2012.07.001

9. Fanara B, Manzon C, Barbot O, Desmettre T, Capellier G (2010) Recommendations for the intra-hospital transport of critically ill patients. Crit Care 14(3):R87. doi:10.1186/cc9018

10. Brunsveld-Reinders AH, Arbous MS, Kuiper SG, de Jonge E (2015) A comprehensive method to develop a checklist to increase safety of intrahospital transport of critically ill patients. Crit Care 19:214. doi:10.1186/ s13054-015-0938-1 